\title{
Approach for siting a support facility for transporting supplies in emergency cases in the Republic of Bulgaria
}

\author{
Emre Demir ${ }^{1, *}$ \\ ${ }^{1}$ Antalya Bilim University, College of Engineering, Department of Civil Engineering, Antalya, Turkey
}

\begin{abstract}
In this paper, the author determines the most suitable transportation location for intervention in a large scale disaster in the Republic of Bulgaria, by means of the Weber Problem and the Weiszfeld method. The objective is to minimise the cost of transporting emergency supplies across the country by locating a support facility, and thus reaching the area of event at the lowest possible cost. A brief description of the Weiszfeld method is provided in the paper. Further, using recent population data of both provinces and municipalities, the method is applied respectively to obtain the results. They were compared in terms of spatial correspondence and the final facility location was fixed. Erecting the supply site is recommended to help decrease the losses.
\end{abstract}

\section{Introduction}

Providing reliable and viable transportation between populated areas is one of the main issues in many countries $[1,2]$. In places where the population density is relatively high, control of the traffic within the area is difficult but important [3, 4]. Especially in the case of a disaster, access to the area is really crucial and vital. Not only natural disasters such as forest fires, landslide, flood, and earthquake, but also large scale man-made disasters can be more effective and harsh as the population grows $[5,6]$. The Republic of Bulgaria does have many facilities in order to intervene under the European Union Civil Protection Mechanism in case of major emergencies and actions requiring urgent response [7]. However, if the event is on a larger scale than expected, the utilities and the equipment may not be enough, and extra support may be needed. Surely, help can come from the neighbourhood of the impact cities or towns, nevertheless the equipment and staff may not be adequate to satisfy the needs in the case of a large scale disaster. For instance, recent forest fires in Greece required extra help and supplies from out of the impact regions and towns. Thus, the concern here is the necessity to supply additional support to the response area in unforeseen circumstances. The necessary service must be provided as soon as possible so that the loss of life and financial loss can be minimised. In this direction, for transporting supplies within the country, a comprehensive support facility that stores the emergency necessities (e.g. first aid equipment deliveries), and includes healthcare professionals is notably needed. Therefore, the motivation to study this problem comes from the need for one large facility with a lot of emergency equipment and crew ready for departure to any part of the country rather than making investment in all towns and cities. Hence, this paper focuses on determining the most suitable transportation location for an intervention. For this reason, a single point facility location is established; therefore techniques in the literature can be applied to solve the case. For example, central median location problem which was used many times in the literature can be functional. In this application, because the sum of the geometric planar distances to the facility location from the demand points is a minimum, the facility location can be simply found. Although, this technique seems simple and viable, it does not include the weights of demand points. Another technique considers the weights of demand points by minimising the weighted Euclidean distances to a single facility location in two-dimensional space, which is introduced by Alfred Weber in 1909 [8], and named as the Weber Problem (WP).

In this research, since the weights of demand points will be taken into account, the most suitable approach to solve our case is by applying WP. In order to solve WP, Weiszfeld has proven in his research that an iterative procedure can be used [9]. This iterative fashion, called Weiszfeld method or algorithm (WM), is accepted as a very powerful method in practice to identify the optimal facility location of WP [10].

In this study, transportation data including costs such as distances are evaluated by the application of WP and WM, and the detected locations are compared. According to the findings, this research is surely instructive to decrease the losses in case of a large scale disaster. The supply site, which is most appropriate in terms of location, to provide service to the regions throughout the Republic of Bulgaria is determined according to the analysis. The following sections of the paper describe the methodology and then explain the use of input data. Finally, the evaluation of the results is presented, and then concluding remarks and further research are exhibited at the end of the paper.

\footnotetext{
*Corresponding author: emre.demir@antalya.edu.tr
} 


\section{Methodology}

In this paper, the methodology includes the solution of WP which is an operational research that was made by Alfred Weber in 1909, as mentioned in [8]. In this operation research problem, the optimization of location is the main purpose. WP is mainly solved by minimising the weighted Euclidean distances in order to find an optimal location serving the demand locations [11-14]. A brief description of WP can be seen as follows.

$$
\min _{\bar{x}} \sum_{j=1}^{n} w_{j}\left\|\bar{x}-\overline{x_{j}}\right\|
$$

The description of (1) is subject to, $\bar{x}=(x, y)$ which is the coordinate of optimum location that is desired, and $\overline{x_{J}}=\left(x_{j}, y_{j}\right)$ which denotes the particular demand point location of $j$ where $j=1, \ldots, n$. Therefore, by subtracting $\bar{x}$ from the location data of $\bar{x}_{\jmath}$, the optimisation process can identify the amount of the distance in between two locations. Moreover in the formula (1), the weight of a specific demand point is introduced by $w_{j}$. In other words, $w_{j}$ stands for the importance of the particular location point of $\bar{x}_{j}$ compared to the other location points. Additionally, all of the location points (i.e. $\bar{x}$ and $\overline{x_{J}}$ ) in the description (1) are the points of the surface of $E^{2}$ which is the Euclidean plane called in older literature. It is the two dimensional space of real numbers (i.e. commonly denoted by $R^{2}$ ). Finally, the minimisation of the multiplication of the particular distances and the related weights is completed. Thus the optimization of (1) discovers the most suitable location of $\bar{x}$.

WP provides a useful mathematical problem to apply in many regional location assessments. Most importantly, WP can be solved by WM, which was built by Enrich Weiszfeld $[9,15,16]$. In the market, there are computer programs which are used for running and achieving solutions from WM. Because the computer program of LINGO can achieve the solution of WP by applying WM $[10,17]$, it is used as a tool for analysing the location and thus optimizing this research. Moreover, it analyses and detects the optimum location of a solution point with regards to the weighted Euclidean distances of demand points in a predetermined surface of a topography [18]. The program does not stop running the iterations, until all the demand points in the analysis are satisfied in terms of their weights [19]. Whenever the solution location does not change according to the iterations running repeatedly, the iterations are stopped and the final decision of the optimization is reported by the program.

As discussed previously, WP which is a mathematical problem for solving transportation related problems, one way of assessing the solution is to apply WM. Since the locations of cities and their weighted importance (i.e. including the population of the provinces, the population in the territories of municipalities, etc.) are the inputs, the methodology discussed in this section can be applicable for the problem of this research. Related formulation of the aim can be found as follows:

$$
\begin{aligned}
\min & {\left[a_{r 1} \sqrt{\left(X_{l o c}-x_{r 1}\right)^{2}+\left(Y_{l o c}-y_{r 1}\right)^{2}}+\right.} \\
& a_{r 2} \sqrt{\left(X_{l o c}-x_{r 2}\right)^{2}+\left(Y_{l o c}-y_{r 2}\right)^{2}}+\cdots+ \\
& a_{r n} \sqrt{\left.\left(X_{l o c}-x_{r n}\right)^{2}+\left(Y_{l o c}-y_{r n}\right)^{2}\right]} .
\end{aligned}
$$

The formulation of (2) is subject to some variables which are described as follows:

$\left(X_{l o c}, Y_{l o c}\right)$ the most suitable location of the facility;

$n$ the number of demand points;

$i=1,2, \ldots, n$ the demand points from 1 to $n$;

$\left(x_{r i}, y_{r i}\right)$ the spatial coordinates of the demand points from 1 to $n$;

$a_{r i}$ the total demand of the demand points from 1 to $n$;

$D_{i}$ Euclidean distance to $\left(X_{l o c}, Y_{l o c}\right)$ :

$$
D_{i}=\sqrt{\left(X_{l o c}-x_{r i}\right)^{2}+\left(Y_{l o c}-y_{r i}\right)^{2}}
$$

$a_{r i} D_{i}$ weighted Euclidean distance to $\left(X_{l o c}, Y_{l o c}\right)$ :

$$
a_{r i} D_{i}=a_{r i} \sqrt{\left(X_{l o c}-x_{r i}\right)^{2}+\left(Y_{l o c}-y_{r i}\right)^{2}} .
$$

As the aim function (2) is regulated in the following with a constraint of $\left(X_{l o c}, Y_{l o c}\right) \geq 0$ :

$$
\min \sum_{i=1}^{n} a_{r i} D_{i} \text {. }
$$

Basically, as can be seen in the formulation of (5), the purpose is to minimise the cost which is the distance for all demand points within the scope of the research. As the formulation of (5) is revealed via WM, the following section describes the scope of the input data as well as the use of data including the conversions and the necessary processes.

\section{Input data}

The input data is provided by inspecting the report titled "Cities and their urbanised areas in the Republic of Bulgaria" which is prepared by the National Statistical Institute [20]. The number of people (population), in this research, is used to represent the amount of demand at each city in an emergency case. Furthermore, the transportation costs such as distances between the attraction areas (i.e. populated cities) are used in the evaluation. In this study, the cost of the Euclidean distance is considered only. The main reason of using Euclidean distances is that immediate help or emergency support can be provided faster by air transportation such as the transportation by means of helicopter. For discovering the cost, the Euclidean distances between the attraction areas are computed by a Mercator projection conversion, because of the geoid shape of the Earth. Therefore, the coordinate of a location can be used as it is on a rectangular $(x, y)$ projection [21]. The coordinates of the locations can be entered the equations of (6) and (7) in order to convert them on a rectangular projection:

$$
\begin{aligned}
& x=\pi R\left(\lambda^{\circ}-\lambda_{0}^{\circ}\right) / 180^{\circ} ; \\
& y=R \ln \tan \left(45^{\circ}+\Phi^{\circ} / 2\right) .
\end{aligned}
$$


For this computation, $x$ (the rectangular coordinate on $x$-axis), $y$ (the rectangular coordinate on $y$-axis) can be found by using $R$ (the radius of the sphere), $\lambda^{\circ}$ (the latitude in degrees), $\lambda_{0}{ }^{\circ}$ (the central latitude in degrees), and $\Phi^{\circ}$ (the longitude in degrees). With the help of the conversion, WM can be applied for the location analysis on a rectangular projection.

\subsection{Data of provinces}

There are 17 provinces in total as described in the documentation of "Cities and their urbanised areas in the Republic of Bulgaria" [20], and this information was used as the inputs in this paper. As described in the report published by the National Statistical Institute [20], a new spatial concept of 'city' is assigned to the territories in the Republic of Bulgaria, therefore, these 17 provinces are accepted as representing the country. Thus the population data from that report can be used as input in this paper. Table 1 indicates a number of examples of provinces and the population in thousands (i.e. demand) related.

Table 1. Population data of the provinces [20].

\begin{tabular}{|l|r|}
\hline Examples of provinces & $\begin{array}{c}\text { Population in } \\
\text { thousands (demand) }\end{array}$ \\
\hline Area with centre city Blagoevgrad & 96.873 \\
\hline Area with centre city Burgas & 279.478 \\
\hline Area with centre city Varna & 411.302 \\
\hline Area with centre city Veliko Tarnovo & 88.455 \\
\hline Area with centre city Vidin & 66.818 \\
\hline Area with centre city Vratsa & 73.767 \\
\hline Area with centre city Dobrich & 114.053 \\
\hline Area with centre city Pazardzhik & 117.293 \\
\hline Area with centre city Pleven & 166.683 \\
\hline Area with centre city Plovdiv & 550.289 \\
\hline
\end{tabular}

The other input material, which is the spatial information (i.e. coordinate evidences), was taken from Google Maps. The spatial coordinates of the central cities of the provinces were provided. Then the location information is converted to a rectangular projection as discussed earlier, in order to input the data into WM.

\subsection{Data of municipalities}

According to the report [20], there is a total of 58 municipalities forming those 17 provinces in the country. In this paper, therefore, the data of these 58 municipalities is also used. Since each province is composed of particular municipalities and their particular areas, the total population of the municipalities must be equal to the population of a specific province. For instance, the total population of the province of Blagoevgrad (i.e. area with central city Blagoevgrad in Table 1) comprises the population of three municipalities named Blagoevgrad, Simitli, and Kocherinovo (Table 2). As can be seen in Table 2, the population data in thousands which are demands from a couple of municipalities are indicated. Additional to the demand data, the coordinate information of the municipalities were again taken from Google Maps.
Table 2. Population data examples of the municipalities [20].

\begin{tabular}{|l|r|}
\hline Examples of municipalities & $\begin{array}{c}\text { Population in } \\
\text { thousands (demand) }\end{array}$ \\
\hline Blagoevgrad & 76.927 \\
\hline Simitli & 14.486 \\
\hline Kocherinovo & 5.460 \\
\hline Aytos & 29.508 \\
\hline Burgas & 209.224 \\
\hline Kameno & 11.258 \\
\hline Sozopol & 14.020 \\
\hline Sredets & 15.468 \\
\hline Avren & 8.835 \\
\hline Aksakovo & 21.218 \\
\hline
\end{tabular}

\section{Results}

In order to obtain the results the data were processed in an optimisation software called LINGO 17.0 x64 [17]. The objective function (5) was entered into the software to get the results using a computer with the properties of Intel ${ }^{\circledR}$ Core ${ }^{\mathrm{TM}}$ i7-2640M CPU @ 2.80GHz.

As mentioned earlier, the optimisation processes are carried out for both the data of the provinces (Table 1) and the municipalities (Table 2). When the process is completed by the inputs of the 'provinces', the coordinate of $\left(X_{l o c}, Y_{l o c}\right)$ (i.e. the optimum location) is found as $(0.7426740,0.4432869)$. This spatial location (LocationA) corresponds to $\left(42^{\circ} 33^{\prime} 07.5^{\prime \prime} \mathrm{N}, 24^{\circ} 36^{\prime} 19.2^{\prime \prime} \mathrm{E}\right)$ in Mercator projection (Table 3). In Location-A, there is not a facility for delivering emergency support in the case of a large scale disaster in the country (Fig. 1).

Table 3. Summary of Location-A and Location-B results.

\begin{tabular}{|l|c|c|c|}
\hline \multirow{2}{*}{ Data } & \multirow{2}{*}{ Location } & \multicolumn{2}{|c|}{ Location coordinates } \\
\cline { 3 - 4 } & & Latitude & Longitude \\
\hline Provinces & $\mathrm{A}$ & $42^{\circ} 33^{\prime} 07.5^{\prime} \mathrm{N}$ & $24^{\circ} 36^{\prime} 19.2^{\prime \prime} \mathrm{E}$ \\
\hline Municipalities & $\mathrm{B}$ & $42^{\circ} 33^{\prime} 15.8^{\prime} \mathrm{N}$ & $24^{\circ} 35^{\prime} 39.2^{\prime} \mathrm{E}$ \\
\hline
\end{tabular}

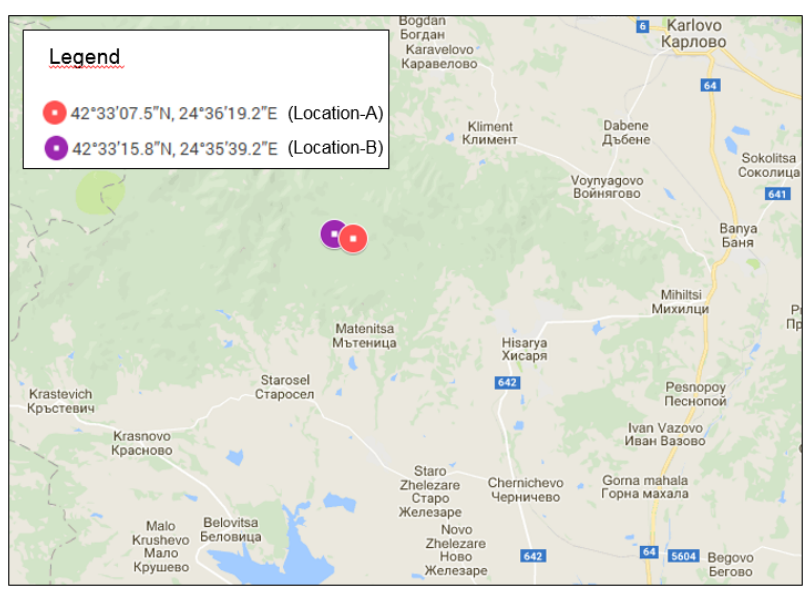

Fig. 1. Ideal locations for siting a support facility according to the data of both provinces and municipalities.

Using the data of the municipalities in Table 2, the location $\left(X_{l o c}, Y_{l o c}\right)$ which makes the transportation distances minimum is again calculated. The result shows that the ideal location (Location-B) is $(0.7427141$, $0.4430738)$ which corresponds to $\left(42^{\circ} 33^{\prime} 15.8^{\prime} \mathrm{N}\right.$, 
24³5'39.2”E) in Mercator projection (Table 3). One can see that, currently, a support facility is not located at the coordinate of $\left(42^{\circ} 33^{\prime} 15.8^{\prime \prime} \mathrm{N}, 2^{\circ} 35^{\prime} 39.2^{\prime \prime} \mathrm{E}\right)$ as well (Fig. 1).

In addition to the results of optimum locations of Location-A and Location-B, the distance between the two results can be also identified. The Euclidean distance between the points is measured as almost 1 kilometre.

Moreover, the verification for both results of Location-A and Location-B, which are the optimal solutions for the datasets of provinces and municipalities respectively, has been done and reported by the LINGO software. For both datasets, the software outputs such as the digital reports of numeric information clearly indicate that the local optimal solutions are found with the number of 0.00 infeasibilities. Although the report (either for Location-A or Location-B) notes that this is a local minima, this local minima is the global minima because our problem is convex. Thus, the results in this research are verified as they are the optimal solutions.

On the basis of these results, the next section presents observations and future work related to the research.

\section{Concluding remarks and further research}

The paper provides an insight to the positioning of a support facility for transporting supplies in emergency cases during or after a large scale catastrophe. By this study, the most suitable transportation location for an intervention against a large scale disaster in the Republic of Bulgaria was determined. The objective to minimise the cost of transporting emergency supplies and reach the area of event sooner from the facility was satisfied. The problem was simulated by a common location problem of WP. Accordingly, WM was applied to find the most optimum solution of the facility location. The main reason of using Euclidean distances between the locations was that the emergency support could be delivered quicker by air transportation (e.g. the transportation mean of helicopter). Last but not least, this paper may contribute to the state planning which is important for the National Disaster Protection Program and also the European Union Civil Protection Mechanism.

From the results of the research, it can be concluded that two locations (i.e. Location-A and Location-B) proposed for siting the facility are relatively close to one another in terms of their spatial correspondence. In other words, the distance (i.e. nearly 1 kilometre) between them is relatively short compared to the size of the country. Because of this topological reason, the site is proposed to erect in between them according to the results of this study. Building the facility which is fully equipped for delivering immediate supply and equipment is highly recommended to help decrease the number of casualties.

For further research, the population of towns and cities included in the census can be surely taken into account in order to rerun WM by using more powerful computer software. Thus, the location difference between the recent result and the future result can be revealed, and therefore further discussion on the facility location can be made.

\section{References}

1. D. Saliev, P. Asenov, Investigation and analysis for work-travels in direct from Pernic to Sofia, BulTrans2009 Proceedings, Sozopol, Bulgaria, 199-202 (2009)

2. J. Chmielewski, T. Szczuraszek, Planning the development of spatial management and transport system of a city from the point of view of environmental impact, MATEC Web of conferences ECCE 2018, 174, 04009 (2018)

3. D. Clark, B. Cushing, Rural and urban traffic fatalities, vehicle miles, and population density, Accident analysis and prevention, 36, 967-972 (2004)

4. S. Hapsari, T. Sjafrizal, R. Anugraha, Designing train passenger seat by kansei engineering in Indonesia, MATEC Web of conferences - ECCE 2018, 135, 00017 (2017)

5. W. Qin, A. Lin, J. Fang, L. Wang, M. Li, Spatial and temporal evolution of community resilience to natural hazards in the coastal areas of China, Natural hazards, 89(1), 331-349 (2017)

6. G. Bakioğlu, H. Karaman, Accessibility of medical services following an earthquake: a case study of traffic and economic aspects affecting the Istanbul roadway, International journal of disaster risk reduction, 31, 403-418 (2018)

7. National Disaster Protection Program 2014-2018, Council of Ministers of the Republic of Bulgaria, Sofia, Bulgaria (2013)

8. A. Weber, Über den standort des industrien, "Alfred Weber's Theory of the Location of Industries", C. J. Friedrich (Interpreter), (University of Chicago Press, Chicago, IL, USA, 1929)

9. E. Weiszfeld, Sur le point pour lequal la somme des distances de $\mathrm{n}$ pointes donnes est minimum, The Tohoku mathematical journal, 43, 335-386 (1937)

10. R. Church, A. Murray, Business site selection, Location Analysis, and GIS, (John Wiley \& Sons, Inc., 2009)

11.L. Tellier, The Weber problem: solution and interpolation, Geographical analysis, 4(3), 215-233 (2017)

12. L. Cooper, I. Katz, The Weber problem revisited, Computers and mathematics with applications, 7(3), 225-234 (1981)

13. J. Brimberg, The Fermat-Weber location problem revisited, Mathematical programming, 71(1), 71-76 (1995)

14. H. Venceslau, M. Venceslau, A. Xavier, N. Maculan, A geometric perspective of the Weiszfeld algorithm for solving the Fermat-Weber problem, RAIRO Operations research, 50(1), 157-173 (2016)

15. U. Eckhardt, Weber's problem and Weiszfeld's algorithm in general spaces, Mathematical programming, 18(1), 186-196 (1980)

16. R. Chen, Location problems with costs being sums of powers of Euclidean distances, Computers and operations research, 11(3), 285-294 (1984) 
17. http://www.lindo.com/index.php/products/lingo-andoptimization-modeling, LINDO Systems Inc. (06.07.2018)

18. K. Aftab, R. Hartley, J. Trumpf, Generalized Weiszfeld algorithms for $\mathrm{Lq}$ optimization. IEEE Transactions on Pattern Analysis and Machine Intelligence, 37(4), 728-745 (2015)

19. H. Üster, R. Love, The convergence of the Weiszfeld algorithm, Computers and mathematics with applications, 40(4), 443-451 (2000)

20. B. Bogdanov, Y. Kalchev, V. Angelova, I. Gavazki, Cities and their urbanised areas in the Republic of Bulgaria, National Statistical Institute, Sofia, Bulgaria (2016)

21. J. Snyder, Map projections - a working manual, U.S. Geological Survey Professional Paper 1395, Washington, USA (1987) 